\title{
Precauções na adoção do método de estudo de caso para o ensino de administração em uma perspectiva epistemológica
}

\section{Precautions about Case Study Method for Management teaching under an epistemological perspective}

André Gustavo Carvalho Machado ${ }^{1}$

Antonio André Cunha Callado²

\section{Resumo}

Apesar dos benefícios do método de estudo de caso como recurso pedagógico, cabe levantar algumas questões de ordem epistemológica em relação ao produto final dessa aprendizagem: a que tipo de aprendizagem ele leva? 0 que ensina? 0 que pode produzir? Tal método capacita para o entendimento de novas situações? De que natureza é a generalização? Para responder a essas questões, foi elaborado um ensaio teórico cujo objetivo é analisar, da perspectiva da produção do conhecimento, o método de estudo de caso para o ensino de administração. A conclusão é de que não se pode tomá-lo como uma panacéia diante de problemas intrínsecos à aprendizagem, tampouco acreditar que seu uso contínuo por si só seja suficiente para que os alunos possam produzir conhecimentos que os capacitem para entender situações que extrapolem as premissas contidas nos casos analisados.

Palavras-chave: estudo de caso; aprendizagem; ensino; conhecimento; método.

Abstract

Despite some benefits regarded to Case Study Method as a pedagogic resource, some epistemological questions still remain unanswered over the overall learning obtained from this approach: What king of knowledge does it lead to? What does it teach? What can it produce? Does it provide the understanding of new situations? What is the nature of generalization? To answer these questions, a theoretical essay was elaborated to aim, from the perspective of knowledge construction, the case study method for teaching management. It concludes that one cannot assume that this method can resolve all problems related to the learning process, neither believe that this could be a stand alone method so that students can construct knowledge as well as make them able to understand situations placed away from the scope of the cases studied.

Keywords: case study; learning; teaching; knowledge; method.

1 Doutor em Administração. Professor Adjunto do Departamento de Administração da Universidade Federal da Paraíba - Programa de Pós- Graduação em Administração - PPGA/UFPB. Endereço: Av. Cabo Branco,1758/701- Cabo Branco - João Pessoa - Paraíba - Brasil -CEP: 58045010. E-mail: andregcm@terra.com.br

2 Doutor em Administração. Professor Adjunto no Programa de Pós-Graduação em Administração e Desenvolvimento Rural da Universidade Federal Rural de Pernambuco - PADR/UFRPE. Endereço: Av. Dom Manoel de Medeiros, s/n. Dois Irmãos - Recife/Pernambuco - Brasil - CEP: 52171-030. E-mail: andrecallado@yahoo.com.br

Artigo submetido em julho de 2007 e aceito em maio de 2008 


\section{Introdução}

A utilização de estudo de casos como recurso de ensino teve sua origem na medicina, ocorrendo pela primeira vez no campo de negócios na Harvard Business School, em 1908, por intermédio do professor Edwin F. Gay. Desde então, muitas instituições têm adotado casos empresariais como parte integrante de suas disciplinas curriculares, entendendo que os mesmos podem contribuir sobremaneira no processo de aprendizagem e, por conseguinte, na produção de conhecimento, preenchendo lacunas que outros recursos pedagógicos não conseguem eficientemente.

Apesar dos benefícios atribuídos a esse método, no âmbito do ensino, ainda há dúvidas de ordem epistemológica quanto aos seus resultados. O que se questiona é: a que tipo de aprendizagem ele leva? O que ensina? O que pode produzir? É um método que capacite o aluno a entender novas situações? De que natureza é a generalização?

Com o intuito de procurar responder a essas questões, foi elaborado um ensaio teórico analisando o método de estudo de caso no ensino, da perspectiva da produção de conhecimento. Entretanto, o objetivo aqui não é realizar um diagnóstico nem tecer maiores comentários sobre o processo de elaboração e aplicação dos casos, ainda que de forma tangencial sejam apresentadas algumas de suas características.

Para a elaboração do ensaio, inicialmente, são sintetizados os motivos comumente defendidos para se adotar o método de estudo de caso no processo de aprendizagem. Em seguida, é discutida sua adequação a uma didática construtivista para a produção de conhecimento. Posteriormente, são apresentadas as limitações do método e o tipo de conhecimento que produz. Por fim, com base nas informações obtidas, são apresentadas algumas conclusões a respeito dos cuidados a serem tomados quando da sua adoção, do ponto de vista epistemológico.

\section{Por que adotar estudo de casos no processo de aprendizagem?}

O método de estudo de caso contribui para o desenvolvimento de certas filosofias, abordagens e habilidades que outros métodos utilizados no ensino não provêem (SHAPIRO, 1988). Essa afirmação se baseia na premissa de que o melhor modo de adquirir uma habilidade gerencial não é valendo-se de uma coleção de técnicas e conceitos, mas pela prática adquirida num processo do tipo simulação. Hammond (2002, p.3) comunga da mesma opinião, quando afirma que "[...] enquanto os conhecimentos obtidos dos livros e leituras podem ser valiosos, os ganhos reais vêm da prática da análise de situações reais de negócios". Nesse sentido, Shapiro (1988) entende que o método deve ser concebido em torno dos conceitos de metáfora e simulação; isto é, cada caso deve ser uma descrição de uma situação real e servir como uma metáfora para um particular conjunto de problemas.

Dessa forma, os estudantes aprendem à medida que analisam as situações apresentadas e desenvolvem um plano de ação para resolver as causas fundamentais dos problemas expostos. Além disso, durante as discussões empreendidas, exercita-se a capacidade de argumentação entre os participantes, ao mesmo tempo em que são compartilhadas as experiências do grupo.

O propósito das discussões em grupo não é, todavia, alcançar um consenso, mas sim contribuir para refinar e ajustar posicionamentos, ao mesmo tempo em que procura preencher lacunas de conhecimento. Afinal, a administração não é uma ciência exata. Não existe (ou deveria existir) uma única solução correta para os problemas que se apresentam. Ao contrário, nos negócios há sempre a possibilidade de que a melhor resposta ainda não tenha sido encontrada.

Com raciocínio semelhante, Hammond (2002) destaca que, desde que sejam produzidas evidências qualitativas e quantitativas que fundamentem as recomendações propostas ao final de cada discussão, os casos ajudam sobremaneira a modelar habilidades analíticas nos participantes. As evidências, por sua vez, são frutos da observação crítica de cada indivíduo, o qual se baseia, fundamentalmente, em suas experiências e expertise. Os resultados finais serão testados pelo grupo e, daí, geradas alternativas úteis de solução. 
Ademais, considerando que os casos estudados envolvem um leque variado de situações organizacionais, acredita-se que o contato com os mesmos produza conhecimento sobre vários assuntos gerenciais, pois os alunos discutem problemas relativos a diversos campos administrativos. Por diferirem de uma empresa para outra, tais problemas (com suas respectivas soluções) acabam dando-lhes subsídios para futuras decisões. Nesse sentido, observa-se um raciocínio indutivo, pelo qual se parte de uma situação particular para uma generalização. Por isso, no entender de Corey (1996), uma visão conjunta de uma série de casos sobre um determinado assunto ajuda a desenvolver conceitos-chave aplicáveis a situações gerenciais específicas.

Corey (1998) discrimina seis elementos que concorrem para o sucesso do aprendizado no método de estudo de caso: descoberta, habilidade de investigação, prática contínua, contraste e comparação e envolvimento e motivação.

O aprendizado pela descoberta se origina do esforço analítico do estudante em filtrar dados úteis dos inúteis e de interpretar e encontrar um significado no conjunto de fatos que compõem o caso. Por outro lado, a descoberta também se dá no momento em que o aluno percebe, por meio das discussões com os colegas de sala, que valores, princípios e modos de pensar sobre certas situações variam consideravelmente de acordo com o background de cada participante. Como resultado, os alunos são levados a reexaminar seus próprios conceitos, reconstruindo seu conhecimento.

O aprendizado por intermédio da investigação visa desenvolver a habilidade de pensar incisivamente, de perceber evidências que não estão claras e de usá-las de forma criteriosa na resolução de problemas.

O aprendizado por meio da prática contínua de resolução de casos possibilita sedimentar certos hábitos de pensamento, formas de visualizar problemas, além de desenvolver habilidades de análise e proposição de ações. Após uma intensa exposição a problemas de natureza diversa, acredita-se que a solução torne-se intuitiva, reduzindo o tempo envolvido no processo.

Contraste e comparação dentro e através das situações problemáticas representam a essência do aprendizado indutivo envolvido no método de estudo de casos. A identificação de elementos comuns entre diferentes casos, entendendo-se por que o que funciona numa situação não necessariamente funcionará em outra, serve para salientar um senso de descoberta. Da perspectiva indutivista, Rangan (1996) salienta que é por meio da comparação entre uma série de casos e o contraste entre estes, que os alunos poderão aprender a construir um framework que permita não apenas entender os casos discutidos, mas também servir (desde que adaptado a diferentes contextos) como uma plataforma útil para abarcar futuras questões relacionadas aos assuntos já abordados.

Diferente dos métodos tradicionais, o estudo de caso exorta o aluno a se envolver, assumindo um papel mais ativo no processo de aprendizagem. Dessa forma, contribui para aumentar a motivação para aprender, a qual é essencial para o sucesso do curso.

Assim, além das habilidades analíticas e interpessoais, Corey (1998) advoga que a utilização de casos contribui para o desenvolvimento das seguintes competências gerenciais: identificação e definição de problemas, coleta e interpretação de dados relevantes, formulação de estratégias, tomada de decisões e trabalho em grupo. A análise de casos também permite que se aprenda a formular as questões certas; ou seja, as questões que estão relacionadas com os fatores estratégicos essenciais ao negócio (HITT; IRELAND; HOSKISSON, 1999).

Tais competências (consideradas críticas), somadas a determinadas competências criativas (tais como imaginar, elaborar e sintetizar), formam o que Jonassen (1996 apud LIMA, 2002) denominou de "pensamento complexo". Na sua concepção, esse tipo de pensamento - aliado a metodologias construtivistas de aprendizagem que privilegiam, ao mesmo tempo, ação, reflexão e colaboração por parte do estudante, e que são situadas em um contexto autêntico de aprendizagem - é essencial para se estabelecer uma visão complexa e interdisciplinar dos problemas organizacionais no processo de formação de gestores.

O fato é que a tomada de decisão para resolução de problemas não envolve apenas uma abordagem racional, com passos lógicos e bem definidos. Ela também envolve a reflexão durante (e não previamente) a ação, a 
intuição, o conhecimento tácito e a contextualização, pois os gerentes se defrontam continuamente com situações dinâmicas, problemas complexos e inter-relacionados e com um ambiente turbulento, marcado por incertezas de curto e de longo prazo.

Diante da constatação de que as aulas expositivas apresentam certa limitação ao desenvolvimento do pensamento complexo nos gestores, Lima $(2002$, p.2) defende que

o estudo de caso parece ser a proposta pedagógica que melhor atende aos princípios construtivistas de aprendizagem ativa, reflexiva, colaborativa e autenticamente contextualizada quanto aos desafios do modelo de pensamento complexo supra-expostos.

Nesse contexto, a próxima seção pretende realizar uma breve explanação sobre a didática construtivista e sua relação com o método de estudo de casos no ensino.

\section{Uma didática construtivista para a produção do conhecimento baseada em casos}

Defende-se que um dos grandes benefícios pedagógicos do método de estudo de casos está na sua capacidade de gerar um alto grau de envolvimento do aluno no processo de aprendizagem, que vem a se refletir no aumento do desempenho em sala de aula, na medida em que ele se sente mais motivado.

Motivar pessoas corresponde, talvez, ao requisito mais discutido entre os profissionais da área de recursos humanos nos últimos anos, principalmente, a partir do momento em que se constatou que esses recursos, quando bem administrados, constituíam-se na principal vantagem competitiva para as organizações. Entretanto, apesar de vários estudos empreendidos na área motivacional, muitas lacunas ainda precisam ser preenchidas. $\mathrm{O}$ fato é que cada indivíduo requer estímulos diferentes para motivá-lo, o que compromete sobremaneira os resultados dos programas implementados, de forma mais ampla, por algumas empresas. Na universidade não poderia ser diferente. O número de desistências, de perda de disciplinas, de mudanças de curso, o absenteísmo, a pequena participação durante as aulas ministradas e o baixo nível de desempenho nos exames escolares são apenas os aspectos mais facilmente mensuráveis de um problema que insiste em desafiar os educadores no momento atual: como motivar os alunos a aprender?

Especificamente quanto ao binômio ensino-aprendizagem, há muitas deficiências que se refletem não apenas na relação aluno/professor, mas também no próprio desempenho profissional do aluno egresso. Assim, motivar os alunos a se esforçarem para aprender não apenas o que é solicitado em sala de aula, mas, principalmente, o que não foi exposto, embora tangencial ao assunto, continua sendo uma tarefa com a qual os docentes se defrontam no seu dia-a-dia.

Nesse contexto, ao se adotar o estudo de caso no ensino, acredita-se que envolvimento e motivação sejam frutos, principalmente, da forma como são transmitidas as informações, parecendo melhor se prestar a uma didática construtivista para o processo de produção do conhecimento. Segundo essa abordagem, a análise de um estudo de caso pode contribuir sobremaneira na construção de novos conhecimentos para o indivíduo, seja por meio de associações ou comparações críticas entre outros casos particulares, seja através de reflexões sobre os seus resultados. Nessa perspectiva, o conhecimento é fruto das interações entre o sujeito e o meio, e o processo de aprendizagem se desencadeia a partir da necessidade do conflito e da inquietação desse sujeito (MACEDO, 1994; ROSA, 1998; SCHWANDT, 1994).

Para Shuell (apud GROHMANN, 2003), no processo de aprendizagem construtivista, não é apenas o conhecimento que está sendo adquirido que tem importância, o conhecimento anterior também deve ser levado em consideração; logo, as experiências acumuladas assumem um papel muito importante nesse processo. No método de estudo de caso, essa constatação é extremamente válida, na medida em que os participantes sacam de suas respectivas experiências para discutirem alternativas de soluções. Entretanto, se a experiência individual contribui para enriquecer as discussões, ela também é um obstáculo para a assimilação de novos conhecimentos, para a transformação da maneira de pensar. 
A mudança de uma forma de conhecimento para outra está intimamente relacionada com o próprio ato de conhecer, com a curiosidade pelo novo, com a necessidade de resposta para questões ainda não compreendidas num determinado momento. O conhecimento resulta do esforço científico por respostas a perguntas formuladas, não da inércia de aceitar idéias dominantes e conservadoras mais para confirmar do que para se alcançar novas dimensões do saber.

Essa inércia, entendida por Bachelard (1996) como "obstáculo epistemológico", é visível, mas mal interpretada nas salas de aula. Não se trata apenas de tentar apresentar novos conhecimentos aos alunos. Mais do que isso (e muito mais desafiante), implica desconstruir verdades sedimentadas pela experiência cotidiana de cada indivíduo, de preencher as lacunas resultantes por meio de argumentos científicos sólidos e, ao mesmo tempo, instigantes o suficiente para despertar o desejo de aprender. Nesse sentido, talvez se deva adotar métodos que se prestem a uma didática mais construtivista, de modo que, por meio do estímulo à participação e à discussão, compreenda-se o estágio individual de conhecimento de cada indivíduo. Além disso, menos do que reproduzir algo dentro de certas condições, repetindo um resultado esperado ou exigido, é muito mais produtivo reconstruir um novo conhecimento. Nesse caso, o papel do professor como questionador, desencadeando perguntas e criando situações-problema, seria de vital importância para a produção de conhecimento.

No construtivismo, assim como no método de estudo de caso, os papéis desempenhados pelo professor e pelo aluno são diferenciados. $\mathrm{O}$ aluno deve ter uma postura ativa, construindo - por meio da reflexão sobre suas próprias experiências pessoais e do relacionamento com o meio e com os outros - suas próprias interpretações, negociando (por intermédio do diálogo) significados e valores e construindo novos conhecimentos. A leitura do caso leva a processar informações oriundas de fatos, a interpretá-las e a discuti-las, chegando-se a conclusões. O professor, por sua vez, mais do que agir como transmissor de informações, torna-se um facilitador, fazendo parte de um processo dialógico no qual o conhecimento passa a ser construído por meio das relações entre mestre e aprendiz. Dessa forma, ele focaliza o "aprender do aluno", pressupondo a existência de uma orientação para os resultados do processo de ensino.

Por outro lado, no modelo não construtivista (e tradicional), o professor é o centro das atenções, adotando uma postura voltada para o "ensinar ao aluno". Este, por sua vez, é constantemente estimulado a ver no professor a figura do grande especialista e único responsável por transmitir a ele, que nada sabe, todo o seu conhecimento e sabedoria. Assim, uma boa aula não construtivista pede o silêncio e a contemplação dos ouvintes, para que o conferencista possa extasiá-los com seus conhecimentos e sua sabedoria. Nesse cenário, menos do que uma comunidade de aprendizes engajados em atividade, discurso e reflexão, as salas de aula, na visão de Palmer (2003), tornam-se dominadas por uma imagem objetivista do saber, fazendo da aprendizagem um processo passivo e triste, transformando as pessoas em espectadores das suas próprias vidas.

\section{Limitações do método de estudo de casos no ensino}

Apesar da exposição de situações reais ser tida como uma das principais virtudes do caso no ensino, Corey (1996) alerta para algumas de suas limitações, quando o caso se presta a ser um instrumento efetivo para trazer uma experiência real para dentro da sala de aula.

Primeiro de tudo, quando o aluno se defronta com as informações dispostas de forma clara e sistematizadas, cria-se a falsa impressão de que as mesmas são de fácil obtenção. Na prática, no entanto, o que se observa é que isso envolve certa complexidade, havendo diferentes fontes para a coleta de dados, tais como: sistemas de informações, reuniões, conversas informais, fornecedores, clientes, consultores, mídia e Internet, entre outras.

Além disso, como destaca Wagner (1991), o processo de aquisição de informação para a resolução de problemas é afetado por diferentes vieses. No nível gerencial, eles incluem:

- distorção no entendimento dos eventos associados ao problema, pela propensão a superestimar aqueles mais freqüentes, subestimando-se os de menor freqüência;

- ponderação diferenciada das informações a serem analisadas, conforme a ordem de chegada das mesmas ao analista; 
- dificuldade de compreender, por diferentes perspectivas, problemas que fujam a um escopo de conhecimento específico, limitando as informações coletadas àquelas relacionadas a um determinado campo de atuação;

- supressão de informações que não se coadunem com a visão do gerente;

- ênfase nas informações concretas (fruto de experiência pessoal), em detrimento de informações abstratas (decorrentes da avaliação de relatórios);

- quando são feitas comparações, propensão a dar maior importância àquelas alternativas que apresentaram maior número de sucessos no passado do que àquelas com uma maior razão entre o número de sucessos e o número de sucessos mais fracassos.

Segundo, o caso é projetado para combinar o tempo planejado para uma aula com o foco sobre uma certa categoria de problemas, omitindo diversos elementos normalmente encontrados numa situação real, tais como interesses pessoais ou grupais, sobreposição de autoridade, stress, cumprimento de cronogramas, atrasos, interrupções etc.

Terceiro, um caso é um instantâneo tomado em um ponto no tempo. Todas as atenções e esforços são demandados para a sua resolução, e apenas após a sua conclusão é que o aluno entra em contato com outros problemas relacionados a casos diferentes. Todavia, na realidade, os problemas gerenciais são freqüentemente vistos como um contínuo; isto é, há uma sobreposição de problemas de diferentes ciclos de vida, que requerem que ações sejam tomadas em paralelo, obedecendo a algum critério de prioridade. Nesse caso, não se espera a finalização de um problema para atuar em outros.

Outra limitação consiste no fato de que no método de estudo de caso, os estudantes são convidados a tomarem decisões sobre alternativas para a solução de problemas, embora não tenham a responsabilidade de implementálas.

Além disso, o processo de resolução de problemas envolve também questões relacionadas às emoções, dúvidas, preocupações, intuições e pressões sofridas pelos recursos humanos numa empresa. Nesse sentido, aspectos políticos e de poder, além dos processos de negociação interna, têm um papel importante no desenvolvimento de planos de ação, pois podem esconder agendas pessoais e modelos mentais, que não podem ser reproduzidos em sala de aula.

Além das limitações ora expostas, constata-se que a utilização de estudo de casos para a produção de conhecimento apresenta algumas deficiências que se refletem tanto na lógica que embasa o método, quanto na própria demarcação científica do conhecimento que se propõe gerar. A próxima seção pretende discutir as questões concernentes a essa afirmação.

\section{Que tipo de conhecimento é produzido por meio do método de estudo de casos?}

Como já mencionado, o conhecimento produzido pelo método de estudo de casos provém, essencialmente, das discussões empreendidas em sala de aula entre os alunos. Estes, por intermédio de observações críticas alicerçadas em suas respectivas experiências, analisam os casos elaborados e propõem alternativas de solução para os problemas apresentados. A expectativa é a de que, após a exposição continuada a uma série de casos que abordam diferentes situações gerenciais - e pela comparação e contraste entre eles -, o aluno esteja apto a decidir, intuitiva e indutivamente, sobre questões relacionadas com assuntos já discutidos. Há, então, um raciocínio indutivo por trás do método adotado, cuja lógica é: "se funcionou, funcionará; se foi, será".

A indução é um processo mental pelo qual, a partir de um certo número de observações, conclui-se algo aplicável a um conjunto mais amplo ou a casos dos quais não se teve experiência. Em outras palavras, partindo de dados particulares, suficientemente constatados, infere-se uma verdade geral ou universal que não consta das partes examinadas (GEWANDSZNAJDER, 1989; MARCONI; LAKATOS, 2000). 
De acordo com esse raciocínio, a observação fornece uma base segura sobre a qual o conhecimento científico pode ser construído, e o conhecimento científico é obtido a partir de proposições de observação por indução. Entretanto, se a base do conhecimento é a observação, como se pode tecer conclusões sobre algo que não foi observado?

$\mathrm{Na}$ tentativa de responder a essa questão, os indutivistas valem-se da lógica e da experiência. Argumentos lógicos caracterizam-se pelo fato de que, se a premissa do argumento é verdadeira, então, a conclusão deve ser verdadeira. Contudo, como alerta Chalmers (1993), os argumentos indutivos não são argumentos logicamente válidos, pois é possível a conclusão de um argumento indutivo ser falsa, embora, as premissas sejam verdadeiras e, ainda assim, não haver contradição. Isso se dá, uma vez que o conteúdo das conclusões é muito mais amplo do que o das premissas nas quais se baseiam.

Sob a justificativa da experiência, acredita-se que se algo funcionou de certa maneira em muitas ocasiões, funcionará de forma semelhante em outras. Sugere-se, portanto, um "salto indutivo"; isto é, a partir de sucessivos exemplos do passado, é feita uma previsão, inferindo-se algo que ainda não ocorreu, que ainda não foi observado. Essa justificação, na ótica de Hume (apud GEWANDSZNAJDER, 1999), é totalmente inaceitável, pois o argumento proposto para justificar a indução é circular: admite-se como verdadeiro, justamente, aquilo que supostamente se pretende demonstrar.

Também na perspectiva de Popper (apud MATTOS, 2003), a indução não possui lógica científica, pois as generalizações não podem ser comprovadas por verificação. Para ele, no entanto, ainda que não possam ser confirmadas, as hipóteses podem ser refutadas pela observação ou pela experiência. Dessa forma, o critério de refutabilidade torna possível justificar com argumentos lógicos e racionais, a escolha por uma teoria científica.

Por outro lado, embora generalizações às quais se chega por induções não possam ser legitimamente verdadeiras, pode-se argumentar que elas provavelmente são verdadeiras. Essa afirmação se fundamenta na premissa de que, quanto maior for o número de observações formando a base de uma indução e maior a variedade de condições sob as quais essas observações são feitas, maior será a probabilidade de que as generalizações resultantes sejam verdadeiras. Todavia, essa reformulação (adotando uma versão probabilística) apenas enfraquece a conclusão inicial e não supera o problema da indução, porque não se esquiva da questão do "salto indutivo" (CHALMERS, 1993).

Outra consideração a respeito do posicionamento indutivista adotado no estudo de caso, refere-se à crença de que a observação crítica produz uma base segura da qual o conhecimento pode ser derivado. "Os fatos falam por si; o caso ensina por si". Teorias, ainda que importantes, têm um papel secundário no processo de aprendizado, pois os ganhos reais vêm da prática da análise de situações reais de negócios.

Sobre esses últimos argumentos, Foester (1996) destaca que apenas vemos o que compreendemos ou, do contrário, não o vemos, pois a observação é conduzida e limitada pelas experiências passadas, por expectativas, hipóteses, problemas e teorias.

Nessa perspectiva, a falta de um embasamento teórico consistente pode limitar sobremaneira a análise das causas dos problemas apresentados, a qualidade das proposições de soluções, a sustentabilidade das conclusões e, por conseguinte, o aprendizado sobre cada caso analisado. Logo, o método de estudo de casos tem que estar associado à teoria que fundamenta as discussões. Não se sustenta a sua dissociação ou marginalização. Como chama atenção Mattos (2003, p.62),

[...] os fatos não falam por si, mas pelo sentido e interpretação que se lhes dá. Sua força ou fragilidade argumentativa está em duas coisas: na sustentação dos conceitos usados para interpretar os fatos e, sobretudo, na estrutura lógica do próprio discurso argumentativo no qual se inserem.

A argúcia do olhar, pois, precedida por uma fundamentação teórica, é fundamental para permitir ver em profundidade, abrindo a percepção para a riqueza e a importância do detalhe, daquilo que apesar de real não está evidente. De forma diferente, corre-se o risco de não identificar problemas quando estes existem ou de propor soluções desconectadas e pouco eficazes. 
Ao se analisar o processo de aprendizagem no método de estudo de casos da perspectiva da troca de experiências entre os participantes, Grohmann (2003), valendo-se de uma abordagem construtivista, assevera que a aprendizagem resulta de processos de reflexão sobre experiências passadas. Dessa forma, num primeiro momento, as experiências concretas vividas pela pessoa irão servir de base para os processos de observação e reflexão. Com esses processos, formam-se conceitos abstratos e generalizações, as quais serão testadas através da experimentação em situações novas. Assim, novos conhecimentos serão construídos.

O pensamento empírico contido no método, todavia, está impregnado pelo bom senso e adota a lógica do senso comum, não atingindo, dessa forma, as características de cientificidade. Essa afirmação se fundamenta nos critérios de demarcação científica defendidos por Pedro Demo para definir o que seria conhecimento científico. Como explica esse autor, o senso comum não pode ser considerado conhecimento científico, pois "se caracteriza pela aceitação não problematizada, muitas vezes crédula, do que afirmamos ou temos por válido" (DEMO, 2000, p.22).

Bachelard também tratou desse assunto, ao alertar para a necessidade de descartar a opinião baseada no empirismo imediato como pressuposto básico para a formação do verdadeiro espírito científico. Para ele, "[...] a opinião pensa mal; não pensa: traduz necessidades em conhecimentos. Ao designar os objetos pela utilidade, ela se impede de conhecê-los" (BACHELARD, 1996, p.18). O espírito científico, pois, proíbe que tenhamos uma opinião sobre questões que não compreendemos, sobre questões que não sabemos formular com clareza. Em primeiro lugar, afirma o autor, é preciso saber formular problemas, pois é a partir deles que se desencadeia toda a atividade científica.

Finalmente, o bom senso, na visão de Demo (2000, p.23), também não pode ser configurado como conhecimento científico, porque aprecia principalmente a intuição

[...] para encontrar, para o momento, a solução mais apropriada, nem sempre brilhante, mas que cabe e resolve. Tem sentido prático eminente e, como a sabedoria, sabe que a vida nem sempre é lógica e matemática, valendo mais a experiência vivida na convivência social e comunitária.

\section{Conclusões}

Diante dos argumentos utilizados pelos defensores da aplicação metódica de estudo de casos no processo de aprendizagem e dos seus benefícios associados, torna-se fácil compreender as razões que permitiram sua popularização não só nos cursos de administração, mas também nos campos do direito, da medicina, da política pública e em outras áreas acadêmicas. Parece não haver dúvidas sobre sua potencialidade para motivar os alunos a uma participação mais ativa nas aulas, a desenvolver suas habilidades de argumentação, de análise e de tomada de decisão.

Não se pode, contudo, tomar o método como uma panacéia para os problemas intrínsecos à aprendizagem, tampouco acreditar que apenas o seu uso continuado seja suficiente para que os alunos possam produzir conhecimentos que os capacitem para entender situações que extrapolem as premissas contidas nos casos analisados. Não parece ser possível. Não parece ser científico. Se for verdade que a análise racional dos fatos e dados que circundam um problema não consegue contemplar a complexidade inerente ao ambiente interno e externo à organização, também é verdade que apenas se pautar pela experiência, contaminada pelo bom senso e pelo senso comum, pode levar a interpretações equivocadas, produzindo soluções inapropriadas para novas situações apresentadas.

Criar frameworks que possam auxiliar a tomada de decisão, como produto da aprendizagem por casos, pode dar a falsa sensação de que a realidade pode ser enquadrada em um modelo, não considerando que este seja apenas uma abstração limitada da primeira. Como construir um arcabouço que tem a pretensão de servir para entender novos problemas, diante da velocidade das mudanças no ambiente empresarial, da mutabilidade das situações gerenciais e operacionais? 
Compreender que o uso de casos pode trazer, de forma sistemática, situações ou problemas reais para dentro da sala de aula, também apresenta, como já comentado, certas limitações. Do mesmo modo, é uma visão míope do processo de aprendizado afirmar que, num processo do tipo simulação, a prática dissociada da teoria seja o melhor meio para gerar conhecimento científico. A disciplina tem que estar associada à teoria que fundamenta as discussões. A teoria tem que estar posicionada de forma independente do método, servindo como um conhecimento de base. É ela que propiciará ao aluno problematizar as situações. A percepção perspicaz do problema é que deflagrará o raciocínio e a investigação científica. De modo diferente, o conhecimento a ser produzido pelo método de estudo de caso será o conhecimento do uso corrente na vida ordinária, o do senso comum, o qual - ainda que seja importante, na medida em que não conseguimos definir e controlar tudo cientificamente - não satisfaz o que se espera do produto final da aprendizagem. 


\section{Referências}

BACHELARD, Gaston. A formação do espírito científico: contribuição para uma psicanálise do conhecimento. Rio de Janeiro: Contraponto, 1996. p.17-28.

CHALMERS, Allan F. 0 que é ciência afinal? São Paulo: Brasiliense, 1993. p.23-63.

COREY, E. R. The use of cases in management education. Boston: HBS Publishing, 1996.

Case method teaching. Boston: HBS Publishing, 1998.

DEMO, Pedro. Metodologia do conhecimento científico. São Paulo: Atlas, 2000. p.13-43.

FOESTER, Heinz von. Visão e conhecimento: disfunções de segunda ordem. In: SCHINITMAN, D. F. (Org.). Novos paradigmas, cultura e subjetividade. Porto Alegre: Artes Médicas, 1996. p.59-74.

GEWANDSZNAJDER, F. 0 que é o método científico? São Paulo: Pioneira, 1989. p.18-62.

GROHMANN, M. Z. Reflexões sobre uma aprendizagem organizacional (parcialmente?) construtivista. In: ENCONTRO NACIONAL DA ASSOCIAÇÃO NACIONAL DOS PROGRAMAS DE PÓS-GRADUAÇÃO EM ADMINISTRAÇÃO, 27., 2003, Atibaia. Anais... Atibaia: Anpad, 2003. 1 CD-ROM.

HAMMOND, John. S. Learning by the case method. Boston: HBS Publishing, 2002.

HIT, Michael A.; IRELAND, R. Duane; HOSKISSON, Robert E. Prepare an effective case analysis. In: Strategic administration. [S.I.]: Thompson, 1999. p.C1-C15.

LIMA, Marcos. Estudos de casos hipertextuais: rumo a uma inovação no método Harvard de ensino de gestão. In: ENCONTRO NACIONAL DA ASSOCIAÇÃO NACIONAL DOS PROGRAMAS DE PÓS-GRADUAÇÃO EM ADMINISTRAÇÃO, 26., 2002, Salvador. Anais... Salvador: Anpad, 2002. 1 CD-ROM.

MACEDO, Lino de. Ensaios construtivistas. São Paulo: Casa do Psicólogo, 1994.

MARCONI, Marina de Andrade; LAKATOS, Eva Maria. Metodologia científica. 3.ed. São Paulo: Atlas, 2000.

MATTOS, Pedro Lincoln. 0 que diria Popper à literatura administrativa de mercado? RAE - Revista de Administração de Empresas, v.43, n.1, p.60-69, jan./mar. 2003.

PALMER, P. Good teaching: a matter of living the mystery. Disponivel em: <http://www.teacherformation.org/pdf/rr_good_teaching.pdf>. Acesso em: 26 maio 2003.

RANGAN, V. K. Choreographing a case class. Boston: HBS Publishing, 1996.

ROSA, Sanny S. Construtivismo e mudança. 6.ed. São Paulo: Cortez, 1998.

SCHWANDT, T. A. Constructivist, interpretivist approaches to human inquiry. In: DENZIN, Norman, K.; LINCOLN, Yvonna S. Handbook of qualitative research. London: Sage, 1994.

SHAPIRO, B. Hints for case teaching. Boston: HBS Publishing, 1985.

An introduction to cases. Boston: HBS Publishing, 1988.

WAGNER, Richard. Managerial problem solving. In: STERNBERG, R. J.; FRENSCH, P. A. Complex problem solving: principles and mechanisms. Hillsdale, NJ: Lawrence Erlbaum, 1991. p.163-175. 